\title{
Circulando en el laberinto: la economía política de la salida del patrón oro en la Argentina (1929-1933)
}

\author{
Pablo Gerchunoff y José Luis Machinea
}

RESUMEN

Este artículo es la pequeña, pero crucial historia de un régimen cambiario-monetario en tránsito durante cuatro años, que culminó en 1933 con la desaparición definitiva del patrón oro en la Argentina. Ese proceso se caracterizó por decisiones tomadas en coyunturas críticas frente a las cuales las autoridades de gobierno no podían andar pausadamente, ante las cuales no tenían un arsenal analítico, ni certezas técnicas, ni convicciones políticas. El objetivo de este estudio es analizar esas "decisiones" a lo largo de siete hitos, siendo el primero el shock externo de 1929 y el último el envío al Congreso de una ley para la creación del banco central y un régimen de control de cambios caracterizado por tipos de cambio múltiples. El nuevo régimen implícito en ese reordenamiento de la economía argentina habría de perdurar, con sus idas y venidas, por al menos un cuarto de siglo. 


\section{I}

\section{Introducción}

Esta no es una historia global de los años treinta — de su política económica con respecto a las funciones del Estado y al patrón productivo- y de las consecuentes transformaciones estructurales, acerca de las cuales ha hecho énfasis una parte de la literatura. Es en cambio una breve, pero crucial historia de un régimen cambiariomonetario en tránsito, que en su etapa final abrió cauce e hizo posibles las transformaciones aludidas. El foco, por lo tanto, no está puesto en el mundo real, sino en el árbol de decisiones de laboratorio que desembocaron en la desaparición del patrón oro en la Argentina. La palabra clave de este ensayo es "decisiones", y estas aluden permanentemente a coyunturas críticas frente a las que los gobernantes no podían andar a ritmo pausado y ante las cuales carecían de arsenal analítico, de certezas técnicas y convicciones políticas. Los cuatro años comprendidos entre diciembre de 1929 y noviembre de 1933 - que son los que aquí se tratarán- encontraron a esas autoridades sumidas casi permanentemente en la incertidumbre y en la ambigüedad, salvo en un punto: la disciplina de la política fiscal habría de ser el ancla macroeconómica, aunque todo lo demás estuviera en cuestión. Se comprende entonces que el proceso decisorio no haya seguido un curso monótono desde el patrón oro a la moneda fiduciaria, sino un avance y retroceso marcado por las contradicciones y la perplejidad. El patrón oro, si bien no siempre fue aplicado, había sido durante décadas una roca inamovible en términos normativos y no fue fácil abandonarlo. Por momentos, la profundidad de la crisis iniciada en 1929 empujó en la dirección del cambio; en otros momentos, el sesgo voluntarista (más que la convicción racional) de que los problemas eran solo transitorios y que se podía apostar a un regreso a la "normalidad" revirtió la marcha. En este último sentido, Raúl Prebisch escribió años más tarde: "En 1931 nunca dejamos de creer que la recuperación estaba a la vuelta de la esquina. Esa es la frase que se decía en todo el mundo: around the corner" (Magariños, 1991).

El título de este artículo ilustra el tema al que se aboca: la política macroeconómica circuló en el laberinto. Metafóricamente, la puerta de entrada al laberinto es el pasado, la vigencia no siempre cómoda, pero finalmente aceptada del patrón oro; la puerta de salida es el futuro, la moneda fiduciaria y el acomodamiento irreversible, y en un principio desconfiado, a una nueva realidad económica mundial y a las nuevas demandas sociales. Los historiadores conocen, sin embargo, que "puerta de entrada" y "puerta de salida" son términos simplistas. En el devenir de los acontecimientos, los actores de la época no perciben que están entrando en un laberinto, tampoco saben que hay una puerta de salida y, de saberlo, bien podrían estar convencidos de que la puerta de entrada es la puerta de salida, esto es, que la puerta de salida es el regreso al patrón oro. No fue así, pero pudo serlo: para los protagonistas, uno de los caminos posibles de la historia es su reversibilidad.

Se anticipan a continuación los hitos en el laberinto, es decir, la secuencia de coyunturas críticas a lo largo de esos cuatro años. En la sección II se presentan los rasgos estilizados del colapso económico a fines de la década de 1920 y comienzos del decenio de 1930; en la sección III se aborda la temprana decisión de Hipólito Yrigoyen de suspender el funcionamiento de la Caja de Conversión en diciembre de 1929, y en las consecuencias que esa decisión tuvo en el tipo de cambio nominal; en la sección IV se analiza la coyuntura nacional e internacional de abril de 1931, el agravamiento de la crisis y la innovación, como respuesta, de redescontar papeles comerciales en la Caja de Conversión, anticipando una de las funciones de un banco central; en la sección V se verá cómo en octubre de 1931, después de la depreciación de la libra esterlina, el Gobierno argentino se asustó de su propia depreciación —asociada a la magnitud del desequilibrio externo y facilitada por la política de redescuentos-e instaló la primera versión del control de cambios del siglo xx para evitar que el valor del peso cayera en exceso; en la sección VI se examina la sorprendente combinación de control de cambios y regreso a la convertibilidad del patrón oro, generada cuando las autoridades ataron el peso al dólar y al franco francés desde diciembre de 1931. Asimismo, la reversión a las políticas tradicionales tuvo todavía un paso más, que se estudia en la sección VII: al revaluarse el oro contra el dólar en los Estados Unidos de América a mediados de abril de 1933, el Gobierno argentino - soportando las presiones deflacionarias - mantuvo el peso anclado al franco, la última de las monedas importantes que persistió en el tipo de cambio fijo contra el oro; ciertamente, aquello no duró mucho y, como queda reflejado en la sección VIII, en noviembre 
de 1933 el zigzagueo concluyó: la Argentina salió del laberinto, la moneda se depreció, el control de cambios se reformó introduciendo tipos de cambio múltiples y se envió el proyecto para la creación del banco central emisor de la moneda fiduciaria. Un nuevo régimen había nacido y duraría al menos un cuarto de siglo.

\section{II \\ El shock externo: El más profundo de la historia en tiempos de paz}

El shock negativo inesperado y profundo con que se inicia esta historia comenzó bien temprano y lo compartieron los principales países productores de materias primas de clima templado: Australia, Canadá y Nueva Zelandia. Cuando a mediados de 1928, la Reserva Federal de los Estados Unidos de América aumentó las tasas de interés para moderar lo que aparecía como un auge económico interno difícil de sostener, hubo dos efectos interrelacionados que con el tiempo se tornarían conocidos y recurrentes: los capitales comenzaron a emigrar hacia el norte y los precios internacionales de los alimentos empezaron a caer como ya había ocurrido, a modo de ensayo general, durante el ajuste antiinflacionario de 1920-1921. La fortuna también jugó en contra de la Argentina por razones climatológicas: las perspectivas de una muy mala cosecha en 1930 aceleraron la fuga de capitales y terminaron por sembrar una incertidumbre que no se vivía desde el estallido de la Gran Guerra. No debe extrañar entonces que al recibirse los cables telegráficos informando a fines de octubre de 1929 sobre el pánico de Wall Street, las autoridades argentinas y los especialistas estuvieran alertas, o en todo caso algo entrenados en el padecimiento. No se trató, pues, de un rayo en un día de sol. No se sabía cuánto tiempo duraría (más bien se esperaba que durara poco), pero estaba claro que había tormenta.

Así fue como se entró al laberinto. Según las estimaciones efectuadas en el presente trabajo ${ }^{1}$, como se puede observar en el cuadro 1, entre 1929 y 1932 (en este último año el nivel más bajo de la década) los precios de exportación argentinos se derrumbaron en $60 \%$, más que los del Brasil, Chile, México y Colombia y levemente menos que los de Australia. En el cuadro 2 se constata que en el mismo período los términos de intercambio cayeron en $35 \%$, casi lo mismo que en Australia. Para la estrategia analítica de este estudio, lo que ocurra entre las puntas del proceso no es necesariamente lo más importante, porque las decisiones en el laberinto se tomaron en coyunturas críticas donde se ignoraba lo que ocurriría después. Vale entonces la pena subrayar

1 En este artículo se utilizan precios de exportación, precios de importación y en consecuencia, términos de intercambio que difieren de los estudios previos (Gerchunoff y Machinea, 2015).

CUADRO 1

Precio promedio de las exportaciones, 1928-1938

(Índice $1929=100$, precios en dólares)

\begin{tabular}{|c|c|c|c|c|c|c|}
\hline Año & Argentina & Brasil & Chile & México & Colombia & Australia \\
\hline 1928 & 109,8 & 106,5 & 103,3 & 100,0 & 113,6 & 111,5 \\
\hline 1929 & 100,0 & 100,0 & 100,0 & 100,0 & 100,0 & 100,0 \\
\hline 1931 & 46,7 & 45,2 & 60,0 & 57,6 & 69,3 & 51,9 \\
\hline 1932 & 39,9 & 48,4 & 41,7 & 56,5 & 54,5 & 36,5 \\
\hline 1933 & 45,8 & 48,4 & 35,0 & 61,2 & 37,5 & 40,4 \\
\hline 1934 & 52,7 & 58,1 & 30,0 & 77,6 & 37,5 & 63,5 \\
\hline 1935 & 52,9 & 48,4 & 30,0 & 74,1 & 30,7 & 50,0 \\
\hline 1936 & 63,3 & 54,8 & 35,0 & 72,9 & 30,7 & 63,5 \\
\hline 1937 & 77,7 & 61,3 & 41,7 & 77,6 & 34,1 & 76,9 \\
\hline 1938 & 70,1 & 41,9 & 31,7 & 56,5 & 30,7 & 69,2 \\
\hline
\end{tabular}

Fuente: Dirección General de Estadística y Censos, Anuario del Comercio Exterior de la República Argentina, Buenos Aires, varios años; Comisión Económica para América Latina y el Caribe (CEPAL), "Relación de precios de intercambio 1928-1976", Santiago, 1977, inédito. 
CUADRO 2

Términos de intercambio, 1928-1938

(Índice $1929=100)$

\begin{tabular}{|c|c|c|c|c|c|c|}
\hline Año & Argentina & Brasil & Chile & México & Colombia & Australia \\
\hline 1928 & 107,4 & 100,4 & 111,3 & 102,4 & 115,5 & 106,2 \\
\hline 1929 & 100,0 & 100,0 & 100,0 & 100,0 & 100,0 & 100,0 \\
\hline 1930 & 89,1 & 64,5 & 95,1 & 90,4 & 73,7 & 80,2 \\
\hline 1931 & 67,5 & 59,6 & 67,2 & 73,4 & 84,0 & 63,6 \\
\hline 1932 & 65,8 & 72,6 & 54,3 & 81,8 & 73,1 & 64,5 \\
\hline 1933 & 66,2 & 66,5 & 61,3 & 85,6 & 63,9 & 65,5 \\
\hline 1934 & 68,4 & 71,0 & 57,9 & 98,8 & 81,5 & 86,5 \\
\hline 1935 & 72,2 & 63,9 & 62,2 & 94,3 & 64,4 & 73,2 \\
\hline 1936 & 93,9 & 72,4 & 70,0 & 90,1 & 64,4 & 92,9 \\
\hline 1937 & 100,7 & 67,4 & 75,3 & 90,6 & 67,1 & 107,3 \\
\hline 1938 & 90,7 & 49,4 & 53,7 & 69,8 & 60,4 & 92,3 \\
\hline
\end{tabular}

Fuente: Dirección General de Estadística y Censos, Anuario del Comercio Exterior de la República Argentina, Buenos Aires, varios años; Comisión Económica para América Latina y el Caribe (CEPAL), "Relación de precios de intercambio 1928-1976", Santiago, 1977, inédito.

que tanto la caída en los precios de exportación, como la de los términos de intercambio no revirtieron en ningún momento hasta 1933. La ironía de la historia fue que la situación empeoraba al mismo tiempo que, a tono con la memoria de un mundo económico más bien beneficioso para la Argentina, las expectativas eran de una vuelta relativamente rápida a la "normalidad" previa. El pasado pesaba.

Por lo demás, las malas noticias no se limitaban a la cuestión de los precios. Lo que iba revelando día a día la crisis en proceso es que las reglas del juego y las prácticas de política económica más o menos imperantes hasta 1929 se ponían en tela de juicio, no tanto todavía en el plano discursivo, pero sí en las decisiones cotidianas de los gobernantes. El comercio internacional se contrajo debido a las tendencias recesivas, pero también a causa de decisiones de política pública que, urbi et orbi, lo afectaron directamente: las reacciones proteccionistas generalizadas, las devaluaciones competitivas y la creciente tendencia al bilateralismo. Los símbolos más notables de ese viraje fueron el arancel Smoot-Hawley, aprobado por el Congreso estadounidense en junio de 1930, y la ley de importaciones inusuales (Abnormal Importation $A c t$ ) del Reino Unido dictada en noviembre de 1931. Los costos no se repartieron de forma equitativa entre las naciones. En el cuadro 3 se observa que la Argentina estuvo entre los países más afectados: el aumento de los aranceles fue mayor en los alimentos que en las manufacturas, y la Argentina, si tenía un rasgo que la distinguía, era el de haberse convertido - merced a su enorme ganancia de participación en los mercados-en el primer exportador mundial de alimentos (véase el gráfico 1). Había sido un proceso de sesenta años que, si bien aún no estaba del todo claro, llegaba a su fin.

CUADRO 3

El aumento del proteccionismo, 1927-1931

(Aranceles de importación en porcentajes)

\begin{tabular}{|c|c|c|c|c|}
\hline \multirow{2}{*}{ País } & \multicolumn{2}{|c|}{ Alimentos } & \multicolumn{2}{|c|}{ Manufacturas } \\
\hline & 1927 & 1931 & 1927 & 1931 \\
\hline Austria & 17 & 60 & 21 & 28 \\
\hline Bélgica & 12 & 24 & 12 & 13 \\
\hline Bulgaria & 79 & 133 & 75 & 90 \\
\hline Checoslovaquia & 36 & 84 & 75 & 90 \\
\hline Finlandia & 58 & 102 & 18 & 23 \\
\hline Francia & 19 & 53 & 26 & 29 \\
\hline Alemania & 27 & 83 & 19 & 18 \\
\hline Hungría & 32 & 60 & 32 & 43 \\
\hline Italia & 25 & 66 & 28 & 42 \\
\hline Rumania & 46 & 88 & 49 & 55 \\
\hline España & 45 & 81 & 63 & 76 \\
\hline Suiza & 22 & 42 & 18 & 22 \\
\hline Yugoslavia & 44 & 75 & 28 & 33 \\
\hline
\end{tabular}

Fuente: Elaboración propia sobre la base de Ronald Findlay y Kevin O'Rourke, Power and Plenty: Trade, War and the World Economy in the Second Millennium, Princeton, Princeton University Press, 2007. 


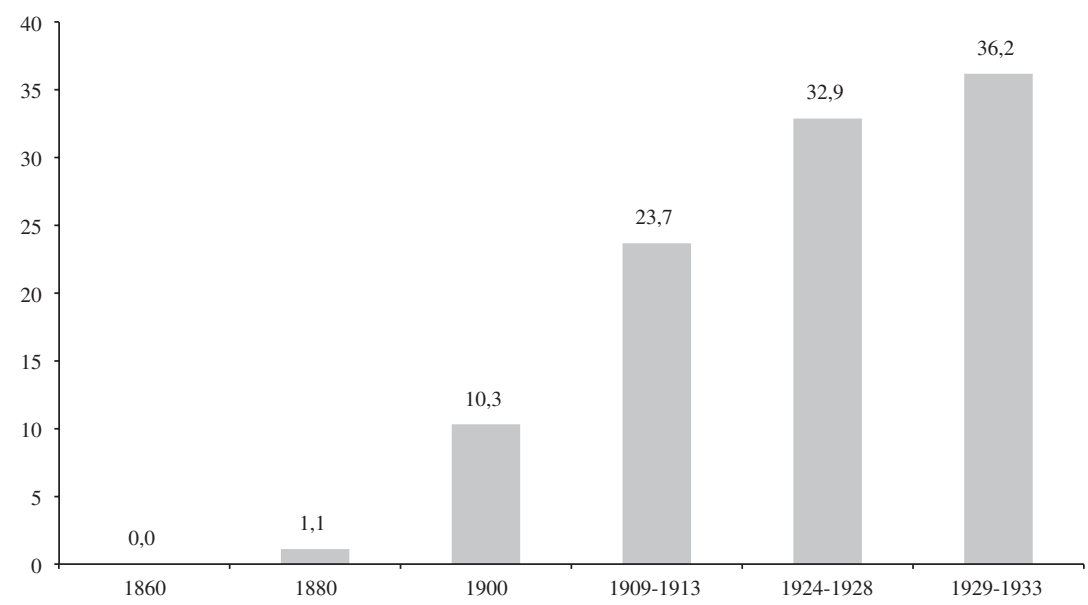

Fuente: Hanson, Trade in Transition: Exports from the Third World, 1840-1900, Nueva York, Academic Press, 1980; y Lois B. Bacon y Friedrich C. Schloemmer, World Trade in Agricultural Products. Its Growth, its Crisis and the New Trade Policies, Roma, Instituto Internacional de Agricultura, 1940.

Nota: Se incluyen los siguientes productos: trigo, maíz, lino, carne, cueros y lana.

\section{III \\ Yrigoyen reacciona temprano: la suspensión de la convertibilidad y la depreciación monetaria (diciembre de 1929-abril de 1931)}

¿Qué hace un gobierno debilitado políticamente, que se enfrenta a novedades adversas y al mismo tiempo no está seguro de que esa adversidad vaya a durar mucho? La respuesta no es obvia. De hecho, puede haber un sesgo hacia la inacción. Ya se señaló en la Introducción que los actores de la época no sabían necesariamente que habían ingresado a un laberinto y, consecuentemente, podían suponer que el libre ajuste del mercado los conduciría a un escenario más tranquilo y conocido. Sin embargo, Hipólito Yrigoyen tomó rápidamente una decisión: en diciembre de 1929 firmó un decreto de suspensión del funcionamiento de la Caja de Conversión. ¿Esa decisión dividió las aguas en el régimen económico? La respuesta debería ser negativa por una razón: en 1876, en 1886 y en 1914 agudas turbulencias de origen interno y externo habían obligado a tomar medidas similares apartando al país de la regla del patrón oro, y en los tres casos se había vuelto a una nueva versión del sistema monetario que casi unánimemente se consideraba deseable. Pero entonces la pregunta es: ¿por qué se tomó la decisión? En este caso, la respuesta es paradójica. Yrigoyen era un hombre acrítico de las instituciones monetarias del siglo XIX, pero esas instituciones le estaban jugando una mala pasada en la coyuntura y optó por cancelar su mecanismo de ajuste en forma provisoria: más precisamente, la pérdida de reservas internacionales estaba reduciendo de manera automática la cantidad de dinero e imponiendo presiones recesivas perjudiciales para cualquiera, pero sobre todo para el líder indiscutido de una joven experiencia democrática.

La decisión de Yrigoyen fue más acertada de lo que él pudo suponer desde entonces hasta su muerte, 
en julio de $1933^{2}$. El cierre temprano de la Caja de Conversión dejó a la Argentina en el primer lugar de la clasificación mundial en términos de oro per cápita, desconectó el circulante monetario de las fluctuaciones del sector externo y abrió cauce a la devaluación nominal de la moneda, el remedio indicado tomando en cuenta la caída de los precios de exportación y la desaparición del financiamiento externo. Y no solo fue el remedio indicado que poco después seguirían casi todos los países del mundo, sino que la oportunidad fue la mejor ${ }^{3}$. Aun así no hubo un exceso de originalidad. De modo similar y casi en simultáneo operaron los restantes productores de alimentos de clima templado: el Uruguay suspendió el funcionamiento de la Caja de Conversión poco antes que la Argentina; desde diciembre de 1928, el Canadá introdujo restricciones de distinto tipo que significaron, en última instancia, el abandono de la convertibilidad ${ }^{4}$; poco tiempo antes, Australia había alentado a los bancos a formar un cartel que proveyera cantidades limitadas de divisas externas. La dinámica de los acontecimientos culminó con la salida de facto de la convertibilidad en diciembre de 1929 (Eichengreen, 1995).

La suspensión de la convertibilidad implicó ingresar de hecho en un esquema de tipo de cambio flotante. Dado el desequilibrio en la cuenta corriente de la balanza de pagos y las dificultades crecientes para acceder al mercado internacional de capitales, la incógnita emergente fue cuál sería la magnitud de la depreciación monetaria. Considerando la gravedad del shock, en un contexto de escasa pérdida de reservas y sin restricciones cuantitativas a las importaciones, la devaluación del $25 \%$ ocurrida entre noviembre de 1929 y diciembre de 1930 fue sorprendentemente moderada (véase el gráfico 2$)^{5}$. A

2 Para un análisis detallado de la decisión de Yrigoyen, aunque desde el punto de vista de este trabajo, que le atribuye un exceso de lucidez sobre los problemas del patrón oro, es útil consultar a Campos (2005).

${ }^{3}$ A diferencia de la Argentina, la mayoría de los países que dejaron la convertibilidad en los meses y años siguiente, lo hicieron cuando las reservas estaban a punto de agotarse.

${ }^{4}$ En diciembre de 1928, el Gobierno canadiense aumentó el costo de la conversión cambiando el lugar de la entrega de oro a Ottawa, y poco más tarde entregando monedas de oro británicas en lugar de estadounidenses. En marzo, los bancos comerciales acordaron con el gobierno no realizar más canjes. Sin embargo, el dólar canadiense volvió a valores cercanos a la paridad durante el segundo semestre de 1930. La convertibilidad recién desaparecería de forma permanente después de la devaluación de la libra en octubre de 1931 (Shearer y Clark, 1984).

5 Como consecuencia de la caída en los precios de exportación y de la mala cosecha, las exportaciones de 1930 fueron menores en 397 millones de dólares a las de 1929, con una reducción del 45\%. Un factor de moderación parcial fue la disminución del $12 \%$ en el precio de las importaciones, lo que significó un ahorro de alrededor ese resultado concurrieron dos factores que permitieron financiar una porción del desequilibrio en el corto plazo. Por una parte, el gobierno y las empresas ferroviarias tomaron préstamos de corto plazo en el ya menguante mercado internacional de capitales (O'Connell, 1984); por otra, muchas firmas se convencieron de que después de algún tiempo las turbulencias cesarían y el peso retornaría a su valor de paridad, y con ese argumento - que se revelaría errado- demoraron la remisión de utilidades y dividendos.

La realidad fue en la dirección contraria. Al comenzar 1931 la crisis mundial se agravó, sobre todo en los Estados Unidos de América. Ya no hubo margen para acceder a crédito en los mercados internacionales y los precios de exportación siguieron cayendo a un ritmo mayor que los precios de importación, todo en un contexto deflacionario que afectaba al balance de los bancos. A pesar de ello, la administración militar que había desplazado del poder a Hipólito Yrigoyen y gobernaba desde septiembre de 1930 decidió reafirmar su compromiso con el orden económico heredado. La decisión que lo dejó en claro fue el anuncio de que se respetaría el cronograma de pagos de la deuda pública. Esa decisión ha sido siempre una fuente de perplejidad para los historiadores. ¿Por qué lo hizo en medio del ahogo financiero estatal, cuando todos los países de la región, excepto Haití y la República Dominicana, ingresaron a la cesación de pagos parcial o total entre 1931 y 1933 ? Hay tres respuestas posibles a ese interrogante y no mutuamente excluyentes. Por una parte, la crisis de 1890, con el incumplimiento que acarreó en los servicios de la deuda, había sido una dolorosa (aunque breve) interrupción en la dinámica del crecimiento argentino y nadie estaba dispuesto a repetir

de 100 millones de dólares. A pesar del superávit de 88 millones de dólares, el déficit de cuenta corriente había sido de 159 millones de dólares en 1929, financiado enteramente por la caída en las reservas internacionales. Para mantener en 1930 el nivel de actividad y el volumen de importaciones de 1929, sin pérdidas de reservas y suponiendo una cuenta capital neutra, era necesario equilibrar la cuenta corriente, lo que significaba reducir el desequlibrio en unos 456 millones de dólares. Esa cifra surge de sumar al déficit de cuenta corriente de 1929 la caída en el valor de las exportaciones y restar la reducción en el valor de las importaciones por la disminución en los precios (100 millones). Dado que las importaciones de 1929 habían sido de 750 millones de dólares y que las exportaciones no reaccionarían en el corto plazo, las importaciones debían disminuir $60 \%$, o sea, alrededor de 450 millones. Lograr una reducción de esa magnitud requería no solo un extraordinario aumento del tipo de cambio, sino también reducir la absorción. En consecuencia, sin recesión ni restricciones cuantitativas, la devaluación que equilibraba la cuenta corriente era sustancialmente más elevada que la que se observaba en los mercados. En parte, ello era consecuencia de que se creía que la situación era transitoria. Sin embargo, la reducción de $18 \%$ de las exportaciones en 1931 mostraría que el desequilibrio era más que transitorio. 
GRÁFICO 2

\section{El tipo de cambio y los principales hitos del laberinto}

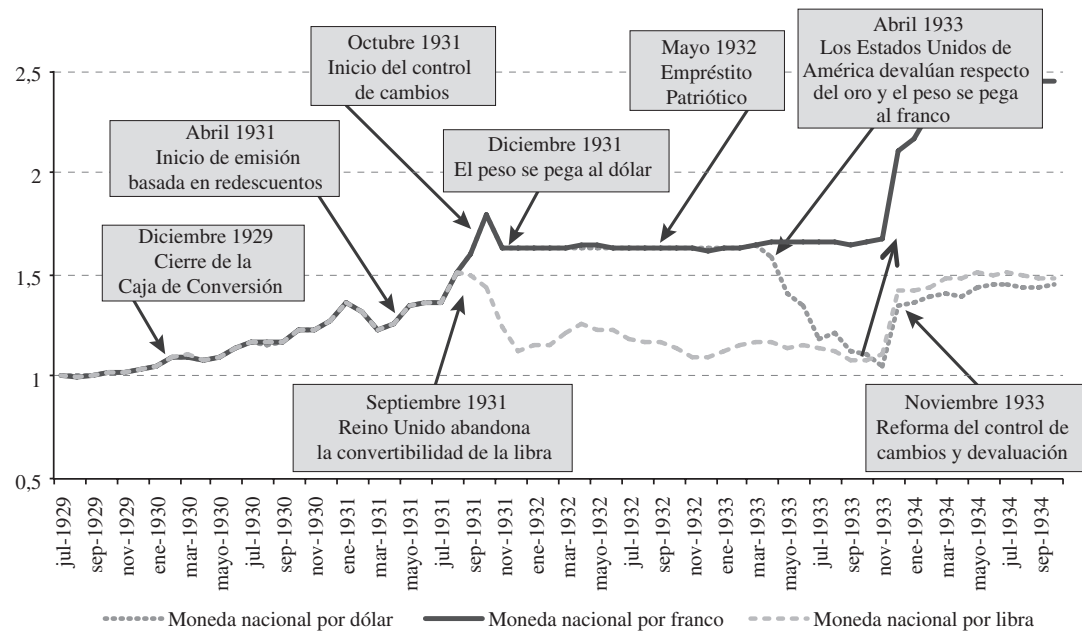

Fuente: Elaboración propia sobre la base de datos de la Revista de Economía Argentina, varios años; National Bureau of Economic Research; y Banco de la Reserva Federal de Saint Louis.

la experiencia. En segundo lugar, la Argentina había sido desde esa crisis "el mejor alumno de la clase", si se mira en perspectiva regional, y "uno de los mejores alumnos" si se lo mira en perspectiva mundial: ¿por qué derrochar la reputación acumulada solo por no hacer un sacrificio que se juzgaba temporalmente limitado? Por último, la clase dirigente todavía no prestaba especial atención a los vecinos latinoamericanos porque pensaba a la Argentina jugando en una liga mayor. En ese sentido, Australia y el Canadá, con una deuda pública entre 2,5 y 3,5 veces más grande, pero con una relación más estrecha con el Reino Unido y los Estados Unidos de América, respectivamente, siguieron pagando sus deudas, al menos con los acreedores externos ${ }^{6}$. Esos eran los ejemplos a seguir.

Más allá de los eventuales costos y beneficios de la decisión de José Félix Uriburu sobre la deuda ${ }^{7}$, hay

\footnotetext{
${ }^{6}$ En el caso de Australia, en el contexto de una profunda recesión y un desempleo que llegó al 30\%, hubo una intensa discusión política, que terminó con la decisión de no restructurar la deuda externa. Dado que no había recursos para pagar toda la deuda, se tomó la decisión de que los tenedores locales contribuyeran al pago de los acreedores extranjeros. Esta decisión fue consensuada con los bonistas locales mediante un referéndum, cuyo resultado fue que el $97 \%$ de esos bonistas estuvo de acuerdo con reducir el interés de los bonos locales en un $22 \%$ y en alargar los plazos de vencimiento hasta en treinta años (Copland, 1933).

${ }^{7}$ Con la sabiduría que da la historia pareciera que los costos fueron mayores que los beneficios, ya que, entre otras cuestiones, la "buena conducta" no resultó en un mayor endeudamiento: hacia 1937 la deuda externa del sector público había disminuido 35\% en relación con 1930.
}

un hecho irrefutable que nos devuelve a los dilemas de política económica tal como los veían los actores de la época, esto es, sin los beneficios (imposibles) de conocer el futuro: pagar la deuda era incompatible con una depreciación más o menos controlada de la moneda. En el contexto de una crisis que se profundizaba y que incluía la imposibilidad de financiamiento externo, el peso se devaluó considerablemente a fines de 1930, y a mediados de enero de 1931 ya había acumulado un $40 \%$ de devaluación con respecto a noviembre de 1929 , momento que se toma como punto de partida de la historia que aquí se narra ${ }^{8}$. Si se quería evitar una devaluación de igual o mayores proporciones y al mismo tiempo honrar la deuda, una alternativa, al menos en el corto plazo, era que los pagos no pasaran por el mercado cambiario, sino que se recurriera al oro de la Caja de Conversión, todavía abundante como consecuencia de la temprana salida de la convertibilidad. Ese fue el rumbo escogido al poco tiempo de que José Félix Uriburu asumiera la presidencia. A ello se agregó la intervención del Banco Nación, que exportó 76 millones de pesos oro mediante compras directas a la Caja de Conversión ${ }^{9}$. El efecto

\footnotetext{
${ }^{8}$ La devaluación del tipo de cambio en términos reales era similar, si se considera como medida de los bienes no comercializados el índice de precios al consumidor en el Reino Unido y los Estados Unidos de América, y el costo de vida en la Argentina.

${ }^{9}$ El Banco Nación actuó en conformidad con el decreto del 31 de enero de 1930, que le permitía la movilización rotativa de su fondo de conversión por medio de extracciones de metálico de la Caja de Conversión (Prebisch, 1932a).
} 
combinado de la reapertura de dicha Caja para pagar deuda pública y de la intervención del Banco Nación permitió por unos meses estabilizar el tipo de cambio a un valor que implicaba una depreciación de solo el $26 \%$ respecto de noviembre de 1929 . Pero esto duró poco: el intento fallido de lograr un empréstito externo en abril de 1931 impidió cerrar el círculo de la política económica a que el gobierno aspiraba. El empréstito hubiera permitido cancelar una fracción significativa de la deuda flotante y lo habría hecho compensando con creces las salidas de oro de la Caja de Conversión a las que se había apelado para reducir la presión sobre el mercado cambiario. En 1876, Nicolás Avellaneda había soñado con un empréstito externo que nunca llegó; en 1890 le tocó soñar a Carlos Pellegrini y ahora a José Félix Uriburu. Es usual que en las crisis se apueste frustradamente a empréstitos de difícil concreción. En este caso, la consecuencia fue una aceleración del ritmo devaluatorio al terminar el primer semestre de $1931^{10}$.

\footnotetext{
${ }^{10}$ Prebisch (1932a) menciona, exageradamente a juicio de los autores de este trabajo, que las tratativas para conseguir un empréstito externo debieron ser dejadas de lado a último minuto a causa de la incertidumbre que habría generado en los mercados financieros el hecho de que el radicalismo, depuesto pocos meses antes, ganara las elecciones para la gobernación de la Provincia de Buenos Aires el 5 de abril de 1931.
}

\section{IV}

\section{La política de redescuentos del Banco Central: abril de 1931}

Entregar oro de la Caja de Conversión a cambio de pesos evitaba la presión sobre el mercado cambiario, pero no la contracción monetaria. Esto tenía un doble efecto nocivo: caía la actividad económica y se deterioraba la salud del sistema financiero, que a esa altura tenía el nivel de reservas más bajo de la última década. En ese contexto, apremiadas por las circunstancias adversas, las autoridades decidieron apartarse de la ortodoxia monetaria o, en términos de la presente narrativa, alejarse de la puerta de entrada al laberinto. Así, a partir del 25 de abril de 1931 permitieron, en medio de ásperas controversias, el redescuento de papeles comerciales en la Caja de Conversión y, consecuentemente, la inyección de dinero en la economía ${ }^{11}$. Desde el punto de vista adoptado en este trabajo, lo que gatilló la medida fueron los aspectos monetariamente contractivos vinculados al pago de la deuda externa. Las memorias de Agustín P. Justo sugieren algo parecido al recordar que se autorizó a los bancos a que "llevaran documentos de su cartera a la Caja de Conversión obteniendo en cambio billetes

\footnotetext{
11 Desde comienzos de siglo y especialmente desde los inicios de la década de 1920, el Banco Nación recibía papeles comerciales de los bancos privados en operaciones de redescuento que no implicaban emisión monetaria. En 1929, los redescuentos del Banco Nación ya explicaban el 16\% de su cartera de préstamos; y en 1931 el 27\%, lo que exigiría la provisión de liquidez por parte de la Caja de Conversión si no se quería poner en graves aprietos al Banco Nación.
}

para reponer los que habían ingresado a la Caja a cambio del oro exportado" (República Argentina, 1938). En un régimen de tipo de cambio flotante, con la Caja de Conversión cerrada, el oro exportado solo había tenido como destino las erogaciones por la deuda pública.

La contracción monetaria asociada al pago de la deuda como principal factor explicativo de la emisión de redescuentos no significa desconocer la situación de emergencia a la que se aproximaban algunos bancos locales y que también afectaba al Banco Nación. Por el contrario, ambos hechos estaban claramente vinculados: con activos que ya sentían el impacto de la recesión y de la deflación, la contracción monetaria solo agudizaba el problema. En el gobierno, particularmente en la cartera de Hacienda, crecía el temor a un colapso del sistema financiero como el que ya se estaba viviendo en los Estados Unidos de América. De hecho, 15 años más tarde, Raúl Prebisch explicitaría su interpretación con respecto a una medida que anticipaba las funciones del Banco Central: "El sistema bancario estaba al borde del colapso y decidimos — yo tuve la idea — resucitar una vieja ley de redescuento bancario que nunca se había aplicado" (Della Paolera y Taylor, 2003, pág. 226) ${ }^{12}$. La medida tuvo algo de preventivo. La caída de los

\footnotetext{
12 La ley de redescuentos a la que se refiere Prebisch es la ley de emergencia de redescuentos de agosto de 1914.
} 
depósitos alcanzaría al 11\% a fines de 1931, pero en marzo-abril, cuando comienzan a operar los redescuentos, era de solo de un $1,5 \%$ respecto de los mismos meses de 1930. Si bien estos datos parecen avalar la idea de que lo que precipitó la emisión de redescuentos fue la absorción monetaria asociada al pago de la deuda, debe tomarse en cuenta que el sistema financiero ya estaba en problemas incluso antes de la contracción de los depósitos. En efecto, en un comportamiento de naturaleza "minskiana", o sea claramente procíclico a través de un mayor apalancamiento para aprovechar la bonanza, los encajes de los bancos privados habían disminuido en la segunda mitad de la década de $1920^{13}$. En los albores de la crisis, la presión sobre las reservas de los bancos aumentó por dos razones: la imposibilidad de recuperar créditos en una situación recesiva y de altas tasas de interés real, y la necesidad del gobierno de colocar deuda flotante en las instituciones financieras dada la caída de la recaudación impositiva ${ }^{14}$. Por otra parte, el valor de las reservas de los bancos es un promedio del sistema, e informaciones parciales sugieren que las dificultades eran mayores en algunos bancos privados nacionales. Asimismo, el Banco Nación tenía agudas restricciones de liquidez. En palabras de Prebisch en su diálogo con Pinedo: "Le expliqué la situación crítica en que estaba el Banco Nación. El Banco tenía los depósitos de la Cámara de Compensación de Cheques, administraba la Clearing House (cámara de compensación). El dinero que el Banco Nación tenía en caja era inferior al dinero de la Clearing. Esto expresa cuál era la gravedad de la situación" (Della Paolera y Taylor, 2003, pág. 226).

En síntesis, en este artículo se pone énfasis en la relación entre el pago de la deuda externa pública y la cantidad de dinero como disparador de los redescuentos, pero el debate acerca de las causas amenaza ser estéril porque, en términos generales, la envergadura de la crisis a comienzos de 1931 empujaba — no necesariamente por convicciones conceptuales, pero seguramente debido a la situación de emergencia - a flexibilizar la relación entre dinero fiduciario y reservas de oro. Desde esa óptica, el redescuento era un instrumento con el que se

13 Las reservas de los bancos disminuyeron de $24,8 \%$ en junio de 1928 a 11,4\% en marzo de 1931.

${ }^{14}$ Los préstamos al gobierno pasaron de representar el 10,7\% de los préstamos totales en 1926, al 20,5\% en 1931. lograban dos objetivos: evitar la contracción monetaria ligada al pago de la deuda y auxiliar a algunos bancos. Asimismo, los redescuentos permitieron durante 1931 una contracción del crédito $(6,2 \%)$ bastante menor que la disminución de depósitos (11,3\%). De todas maneras, la dinámica diferencial entre créditos y depósitos requiere de un ingrediente adicional para su cabal comprensión. El efecto obedece en forma exclusiva al aumento de los préstamos del Banco Nación, ya que, a la inversa, los préstamos de los bancos comerciales disminuyeron en mayor medida que sus depósitos ${ }^{15}$.

La política de redescuentos de papeles comerciales en la Caja de Conversión y la política anticíclica del Banco Nación no se pueden escindir a la hora del análisis de la crisis. Se necesitaban mutuamente para tener alguna eficacia. Algunos autores, en particular Della Paolera y Taylor (2003), han visto en la política de redescuentos un auténtico cambio de régimen macroeconómico, vale decir, la salida del laberinto. Mirado desde el final de la historia, es difícil no coincidir: emergía una política monetaria expansiva frente a las presiones deflacionarias, y lo hacía en el contexto de la flotación cambiaria inaugurada por Yrigoyen y continuada por Uriburu. ¿Qué más hacía falta? ¿No se esperaría a partir de entonces que la deflación revirtiera y que la economía se reactivara aunque fuera con alguna demora? Más adelante, en este artículo se volverá sobre el impacto en los precios y el tema de la reactivación, pero se anticipa que la reactivación no llegó entonces. La causa principal por la que no se produjo fue que no hubo tal cambio de régimen, sino solo una medida aislada. Para que haya un cambio de régimen, este tiene que ser comprendido y sostenido como tal por los actores de la época, y eso no fue lo que sucedió. La política de redescuentos fue un paso más en las idas y vueltas de autoridades desorientadas ante una transformación que estaba ocurriendo ante sus ojos, pero que, como en otras latitudes, no lograban comprender cabalmente. Prebisch (1932a) lo dijo a su manera, expresando que no fue una medida de política monetaria, sino una imposición inexorable de los hechos.

\footnotetext{
15 Como ha estudiado Salama (2000), el Banco Nación actuó en forma contracíclica: aumentó los encajes hasta el 37\% de los depósitos en 1928 y los disminuyó al 27\%, $17 \%$ y $15 \%$ a fines de 1929,1930 y 1931, respectivamente.
} 


\section{V}

\section{Una innovación persistente: control de cambios y tipo de cambio fijo (octubre de 1931-abril de 1933)}

Cinco meses después de instaurada la política de redescuentos, en septiembre de 1931, una tormenta recorrió el mundo: acorralado por una fuerte fuga de capitales, el Banco de Inglaterra, que en 1925 había retornado al patrón oro a la antigua, pero ahora incómoda paridad, se vio obligado a suspender la convertibilidad de la libra esterlina. No se trataba de un "caso periférico", sino de una moneda que todavía competía con el dólar en su intento por mantener la situación de privilegio de ser la principal moneda del mundo, el símbolo de la estabilidad desde mediados del siglo XIX (Eichengreen y Flandreau, 2009). En línea con los países del Commonwealth, con los que tenía algunas similitudes en términos de patrón productivo y de flujos de comercio, la Argentina acompañó el movimiento de la libra y luego, como surge de una nueva inspección al gráfico 2, dejó flotar libremente su moneda por unas semanas, mientras reinaba la confusión asociada a la decisión británica. El resultado fue una importante devaluación adicional con respecto al dólar. En agosto de 1931 esta llevaba acumulada una depreciación del $46 \%$ con relación al dólar en comparación con noviembre de 1929; y en octubre, una del $76 \%$. Probablemente ese orden de magnitud explique por qué la deflación fue menos profunda que en otros países. Entre 1929 y 1932 la caída de precios mayoristas en la Argentina fue del 10,5\%, en Italia del $35 \%$, en los Estados Unidos de América del 32\%, en Francia del $31 \%$, en el Canadá del $30 \%$, en Alemania del 29\%, en Australia del 28\%, y en el Reino Unido del $25 \%$ (Sociedad de las Naciones, 1933).

Después de ese movimiento vertiginoso llegó el inevitable miedo a la flotación. El 25 de septiembre de 1931, en la Bolsa de Comercio de Buenos Aires, el Ministro de Hacienda, Enrique Uriburu, el mismo que había puesto en marcha la política de redescuentos, dejó constancia de su propio viraje: "La depreciación e inestabilidad monetaria es un estado de hecho de la dislocación económica y financiera que hemos recibido. Los emisionistas son un peligro real si se los escuchara" (Revista de Economía Argentina, 1931). ¿Por qué el miedo? Hubo varias razones, pero una predominó ampliamente sobre las otras. Como se ilustra en el gráfico 3, la devaluación le dificultaba al Tesoro de la
Nación el pago de la deuda y asomaba el riesgo de que esos pagos se tornaran inmanejables. Ahora bien, si no se pensaba convalidar la dinámica que había adquirido el tipo de cambio nominal, pero al mismo tiempo el gobierno se confirmaba en su idea de cumplir con las obligaciones financieras externas, un nuevo riesgo emergía: la caída de las reservas internacionales en medio de una espiral contractiva. Para neutralizarlo, las autoridades económicas apelaron a una innovación institucional que acompañaría a la historia económica del país durante casi tres décadas sin interrupciones: el control de cambios. En su versión inicial, el control de cambios nació mediante un decreto del 10 de octubre de 1931 y apuntó a una administración cuantitativa de las divisas disponibles. El orden de prioridades para acceder al mercado cambiario fue el siguiente: i) obligaciones externas del gobierno nacional y de los gobiernos provinciales y municipales; ii) materias primas, combustibles y artículos de consumo imprescindibles; iii) remesas de inmigrantes y gastos de viajeros; iv) mercaderías no imprescindibles, incluidos bienes de capital, remesas de utilidades y dividendos de empresas extranjeras. Al respecto, vale la pena subrayar dos cosas. Por una parte, la absoluta prioridad de los pagos de la deuda pública y, en línea con un escenario de insuficiencia de demanda, la absoluta falta de prioridad en los bienes de capital; por otra parte, el hecho de que, si iba a haber un tipo de cambio fijo y los requerimientos de divisas no se satisfarían en su totalidad, habría restricciones cuantitativas y consecuentemente surgiría un mercado paralelo.

En los hechos, durante unas semanas el control de cambios coexistió con el tipo de cambio flotante, de modo que hubo acceso pleno a las divisas aunque a precios crecientes y sin mercado paralelo. El gobierno apostó en ese momento a que, como resultado de una negociación con los bancos locales, el tipo de cambio se estabilizaría. Las negociaciones fracasaron y como consecuencia se decidió la estabilización unilateral y la aplicación de las restricciones cuantitativas según las prioridades mencionadas. La forma en que se hizo, sin embargo, deja en claro que el gobierno vivía entre dos mundos. En diciembre de 1931, se resolvió atar el peso al dólar y al franco francés, las dos monedas importantes 
que prolongaban su permanencia dentro de un régimen de patrón oro. Una rareza se consumaba: el control de cambios, administrado por una Comisión Mixta, se combinaba con el tipo de cambio fijo, pero el tipo de cambio fijo establecía un nexo con el oro a través del dólar y el franco (véase el gráfico 2). La consecuencia fue una leve apreciación del tipo de cambio nominal y, sobre todo, la expectativa de estabilidad a futuro de ese tipo de cambio. En dos meses se hizo evidente que la reversión de las tendencias deflacionarias había sido solo transitoria; en febrero de 1932 la deflación recobró vigor y así duraría hasta noviembre de 1933 (véase el gráfico 4).

GRÁFICO 3

Intereses de la deuda pública

(En porcentajes)

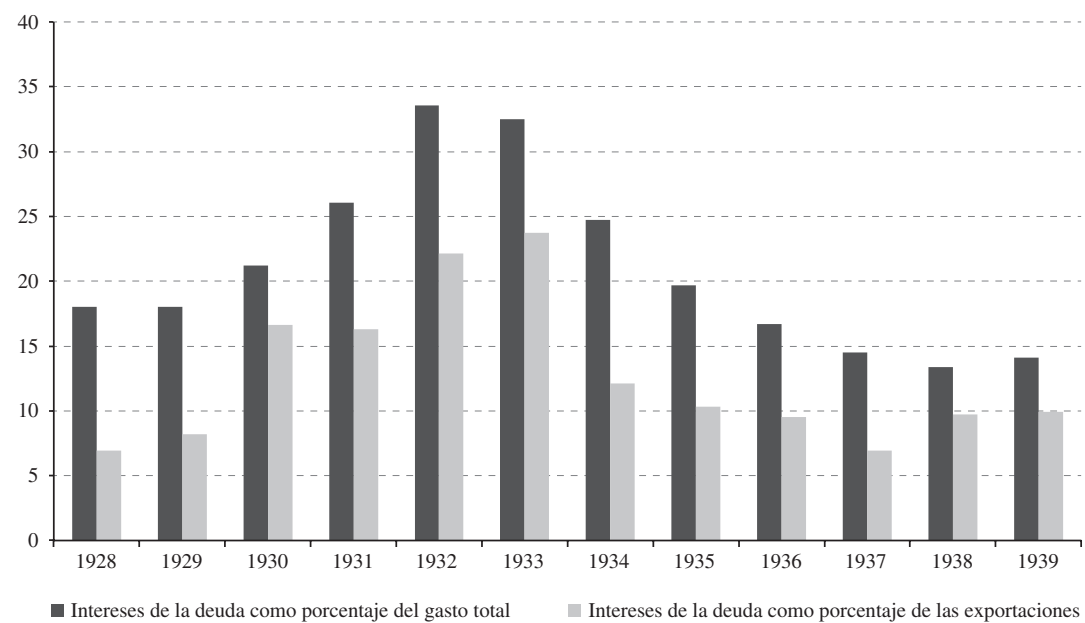

Fuente: Comité Nacional de Geografía, Anuario geográfico argentino, Buenos Aires, 1942.

GRÁFICO 4

La devaluación y los precios mayoristas

(Índices noviembre $1929=100$ )

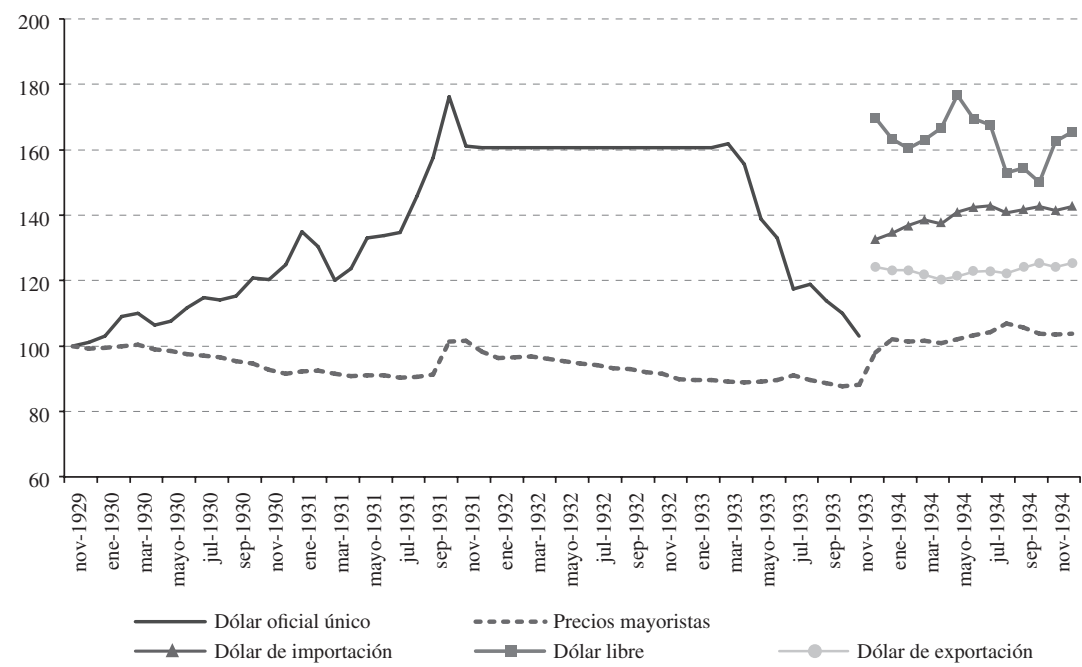

Fuente: Elaboración propia sobre la base de Revista de Economía Argentina, varios años; y Vicente Vásquez-Presedo, Estadísticas históricas argentinas II (comparadas), Buenos Aires, Ediciones Macchi, 1976. 
Este trabajo no es el lugar apropiado para definir si la recesión provocó deflación o si la deflación provocó recesión. Lo cierto es que los efectos de la gran depresión generaban recesión y deflación y, como lo mostraría Keynes poco después, debilitaban la eficacia de la política monetaria. A ello se agregaba el efecto de la deflación en las deudas y, en general, en la demanda (a la Fisher). Ambos efectos agravaron la recesión y la deflación confundiendo todavía más a los funcionarios, entre otros motivos, porque el fisco comenzó a sufrir con mayor intensidad el impacto depresivo. Dominaban las dificultades para que se impusiera la razón. La coherencia interna de esa forzada arquitectura monetaria y cambiaria no era evidente a primera vista. La Argentina adhería de facto al bloque del oro, pero para que esa decisión fuera sostenible sin que se consumieran las reservas - tan abundantes en 1929- había que aplicar restricciones cuantitativas a la venta de divisas según prioridades preestablecidas. Algo parecido estaba haciendo Austria casi al mismo tiempo que la Argentina y así lo terminarían haciendo Alemania, Hungría e Italia. ¿Qué hilo invisible podía unir a la Argentina con esas naciones golpeadas por la guerra y las turbulencias internas? La crisis misma, la sensación de laberinto. En el caso argentino, ¿dónde había quedado la política de redescuentos en la Caja de Conversión, ese golpe de emisión monetaria que pareció ser un cambio de régimen? Tienta decir que lo que tenía de sólido se había desvanecido en el aire. Sin embargo, la depresión era demasiado profunda como para que, en magnitudes menores, no se repitieran ensayos similares. En ese sentido, vale la pena aludir a un ejemplo en la dimensión fiscal. Necesitada de financiamiento, que se hallaba racionado en los mercados de capitales, la flamante administración del Presidente Agustín P. Justo intentó, a mediados de 1932, colocar en el mercado local el así llamado "Empréstito Patriótico" por un monto de 305 millones de pesos. Menos del 50\% (135 millones) fue absorbido por el sector privado, incluidos los bancos comerciales. Los 170 millones restantes fueron papeles colocados en la Caja de Conversión, lo que significa que tuvieron como contrapartida emisión de dinero. De nuevo surge la pregunta: ¿un paso más hacia la moneda fiduciaria o solo una respuesta a la emergencia?

\section{VI}

\section{Patrón oro de facto: el redoblar de la apuesta (abril de 1933-noviembre de 1933)}

El final de la historia del patrón oro en la Argentina — sobre el que se detendrá la próxima sección - solo en parte obedeció a una iniciativa de los gobernantes nacionales. El control de cambios de octubre de 1931 contenía un error técnico de engorrosas consecuencias para las relaciones económicas internacionales y para el manejo macroeconómico, y fue recién durante las negociaciones del Tratado Roca-Runciman que ese error evidenció sus costos y abrió las puertas a una transformación definitiva. El problema fue que el régimen de control de cambios —obra, inevitablemente, de inexpertos- limitó la entrega de divisas demandada por los importadores, pero no así su gasto. En otras palabras, la Comisión Mixta y la propia cartera de Hacienda se preocupaban por el balance cambiario, pero no por el resultado de la cuenta de comercio y el de la cuenta corriente ${ }^{16}$. Se comprometían pagos futuros en divisas, pero cuando llegaba el momento de la erogación no siempre era posible cumplir con los contratos. Eso generó una deuda creciente (véase el cuadro 4), sobre todo con los países con que se mantenía un superávit comercial, en particular el Reino Unido y Alemania. A ello se agregó que, dadas las prioridades del control de cambios, era frecuente que las utilidades y dividendos de las empresas privadas no se remitieran, sino que quedaran congeladas

\footnotetext{
${ }^{16}$ Era obvio en cualquier caso que el régimen de cambios, al generar incertidumbre sobre el acceso a las divisas, producía una restricción a la demanda de importaciones.
} 
Diferencias entre importaciones realizadas y divisas vendidas (En millones de $m \$ n$ )

\begin{tabular}{lcccccccc}
\hline & \multicolumn{3}{c}{1932} & & \multicolumn{3}{c}{1933} \\
\cline { 2 - 3 } \cline { 6 - 8 } & Importaciones & Divisas vendidas & Diferencia & & Importaciones & Divisas vendidas & Diferencia \\
\hline ler semestre & 404,7 & 406,4 & $-1,7$ & & 430,8 & & 388,5 & 42,3 \\
$2^{\circ}$ semestre & 431,6 & 321,1 & 110,5 & & 466,3 & & 273,8 & 192,5 \\
Total & 836,3 & 727,5 & 108,8 & & 897,1 & & 662,3 & 234,8 \\
\hline
\end{tabular}

Fuente: Elaboración propia sobre la base de República Argentina, Poder Ejecutivo Nacional 1932-1938, vols. 1 y 2, Buenos Aires, 1938.

en pesos en bancos locales. La dinámica de esa deuda se convirtió en potencialmente explosiva, porque el propio control de cambios estaba pensado para evitar la depreciación de la moneda y, como argumentaba el diario La Nación, eso estimulaba las importaciones y desalentaba las exportaciones ${ }^{17}$. Bajo esas reglas, no había convergencia a una situación estable.

A esa inconsistencia se sumó a mediados de 1932 el Pacto de Ottawa como factor agravante. Una vez que las preferencias imperiales en materia comercial acordadas por los miembros del Commonwealth $-\mathrm{y}$ que eran una antigua demanda de los socios no británicos- se pusieran en marcha, se limitarían las exportaciones de carne argentina al Reino Unido para beneficio de Australia y de los productores ingleses y escoceses. Las autoridades reclamaron inmediatamente una reconsideración, y con ese objetivo viajó a Londres una delegación encabezada por el Vicepresidente Roca. No se entrará aquí en detalles sobre el Tratado RocaRunciman ${ }^{18}$. En materia comercial, la Argentina pidió $-\mathrm{y}$ consiguió en medida no desdeñable - un trato menos discriminatorio en materia de carnes; por su parte, el Reino Unido pidió - y obtuvo- beneficios comerciales, tales como un tipo de cambio diferencial (más bajo) para las importaciones provenientes de las islas británicas y una reducción de aranceles exclusivamente para sus exportaciones. La Argentina conoció así, de

\footnotetext{
17 En relación con el control de cambios en las semanas previas a los anuncios de noviembre, un editorial de La Nación señalaba: "El mantenimiento de los servicios de la deuda, sin realizar ninguna tentativa de arreglo para su reducción, el mantenimiento del cambio, sin comprender de que se daba un privilegio a la importación a costa de la exportación; la creciente preferencia que se otorga a los permisos de remesas para pago de la deuda pública son, a nuestro modo de ver, hechos que están en contra del país". Reproducido en Revista de Economía Argentina (1933).

18 Para una evaluación del tratado, que oficialmente se denominó Convención y Protocolo sobre Intercambio Comercial con Gran Bretaña e Irlanda del Norte, véase Fodor y O’Connell (1973).
}

primera mano, la dureza del bilateralismo británico ${ }^{19}$. Nadie como John Maynard Keynes fue tan transparente para explicar esa política que a todas luces ahondaba el deterioro de los términos de intercambio argentinos: "Queremos carne y pagaríamos 110 libras por ella; la Argentina desea un auto que cuesta 110 libras en el Reino Unido y 100 en Estados Unidos; Estados Unidos no quiere la carne, tiene un arancel contra ella y no pagaría más de 50 libras, como máximo; la Argentina tiene la carne y aceptaría contenta 100 libras por ella antes que no venderla, pero no está dispuesta a aceptar menos de 100; nosotros, que no tenemos dólares, sólo podemos comprar la carne si vendemos el automóvil. Bajo un sistema de libre comercio el intercambio no se realiza, ya que si pagamos la carne con dinero, sea a 100 o a 110, la Argentina gastaría ese dinero comprando un auto en Estados Unidos, y nosotros quedamos insolventes. Algún sistema por el cual nuestra compra de carne dependa de que la Argentina compre nuestro auto es el único camino por el cual puede realizarse el intercambio. De otra manera, los productores argentinos de carne y nuestros productores de automóviles quedan ambos sin trabajo" (De Paiva Abreu, 1984).

La mayor parte de la historiografía se ha concentrado en un apasionado debate sobre estos aspectos comerciales del Tratado. Sin embargo, igualmente relevantes fueron los aspectos financieros, derivados justamente de la deuda argentina que las deficiencias del régimen del control de cambios de octubre de 1931 habían generado. En ese sentido, el Reino Unido obtuvo en la negociación correcciones al régimen del control de cambios para que la acumulación de deudas no se repitiera; consiguió,

\footnotetext{
${ }^{19}$ Los Estados Unidos de América, con una posición comercial con respecto al Brasil similar a la del Reino Unido respecto de la Argentina, también ejercieron presión sobre el Brasil para obtener ciertas ventajas comerciales y vinculadas con la deuda. Sin embargo, pese a las negativas brasileñas a acceder a esas peticiones, nunca llegaron a apelar a medidas coercitivas concretas (De Paiva Abreu, 1984).
} 
además, que el pago de deudas vencidas y futuras se cancelara a un tipo de cambio privilegiado respecto de otros acreedores ${ }^{20}$. La Argentina, por su parte, obtuvo la emisión de un "préstamo de desbloqueo" en libras a una tasa del $4 \%$ para hacer frente al pago de esas deudas ${ }^{21}$. Además, el Gobierno argentino también recibió un monto equivalente a los montos utilizados en el desbloqueo en "calidad de préstamo suscripto por el inversor británico, teniendo la posibilidad de expandirlo a su total discreción". Esos recursos fueron usados para pagar deuda flotante y para recomprar deuda pública, como parte de un proceso de reestructuración de la deuda interna que encararía el gobierno. Dada la decisión irreversible de mantenerse al día con las obligaciones externas, la ausencia de ese empréstito no solo hubiese provocado una mayor depreciación de la moneda (lo que a esa altura se procuraba evitar), sino que también hubiera dificultado la reducción de las tasas de interés y consecuentemente la reconversión de la deuda interna (Alhadeff, 1985).

Mientras se llevaban adelante las negociaciones entre la Argentina y el Reino Unido, con sus claros y oscuros, Franklin D. Roosevelt asumió la presidencia de los Estados Unidos de América y tras sesenta días de

20 Como se verá enseguida, el pago de dividendos e intereses en el futuro se haría en su totalidad por el tipo de cambio oficial, ventaja a la que no accedían otros países, el más importante de los cuales era los Estados Unidos de América.

21 Esto implicó una compleja ingeniería financiera. Los titulares de fondos bloqueados recibieron títulos del gobierno que fueron comprados por la flamante compañía The Argentine Convention Trust, que a su vez se financió con certificados colocados en el mercado británico (Cortes Conde, 2014). corridas bancarias y fuga al oro decretó el abandono de la paridad del dólar con el metal. Ante esa decisión, el Ministro de Hacienda argentino, Alberto Hueyo, reaccionó con un último gesto de ortodoxia monetaria: no solo pegó el peso al franco francés, último baluarte del patrón oro, sino que - a diferencia de lo ocurrido con la depreciación de la libra- esta vez impidió que el peso acompañara al dólar. En otras palabras, a pesar de los problemas del sector externo, se decidió apreciar el peso con respecto al dólar y con respecto a todas las monedas que se depreciaron con el dólar. No es fácil encontrar una explicación para esta decisión, excepto una excesiva ponderación del peso de la deuda, ahora aumentada por los empréstitos británicos ${ }^{22}$. Pero que no se encuentre una explicación convincente no significa que las convicciones del ministro no fueran profundas. Respondiendo a una interpelación del senador Matías Sánchez Sorondo, Hueyo rechazó contundentemente la depreciación: "La alarma, el pánico, pueden conducir a una catástrofe. El gobernante en esas condiciones semeja al maquinista que en veloz carrera ha perdido el control de su máquina, y dudo que haya un argentino que conociendo antecedentes financieros nuestros, no sintiera temblar su mano al firmar un decreto de desvalorización, pensando en el caos que un hecho de esa naturaleza puede ocasionar en la economía de un país" (Congreso de la Nación, 1933).

\footnotetext{
${ }^{22}$ De hecho, la renuncia posterior de Alberto Hueyo estuvo motivada por su desacuerdo con la decisión de Agustín P. Justo de tomar el empréstito.
}

\section{La salida del laberinto: moneda fiduciaria y control de cambios reformado} (noviembre de 1933)

El apego de Hueyo por el patrón oro fue un episodio fugaz y a todas luces anacrónico. En agosto el ministro abandonó el cargo y fue reemplazado por Federico Pinedo, el representante del Partido Socialista Independiente en la Concordancia tras la muerte de De Tomaso. En noviembre de 1933, Pinedo, secundado por Raúl Prebisch, anunció su Plan de Acción Económica. En un intento de revertir la apreciación cambiaria — con respecto a noviembre de 1929 el peso estaba depreciado apenas un $5 \%$ - las autoridades dieron lugar a una devaluación de alrededor 
del $20 \%$ para las exportaciones tradicionales y del $30 \%$ para las importaciones con permiso de cambio ${ }^{23}$. Casi simultáneamente se anunció el envío al Congreso de un proyecto de ley orientado a crear un banco central mixto que tomaría a su cargo la administración de la política monetaria. Un rasgo original era que esa política monetaria se vertería en el molde de un control de cambios de nuevo tipo, con el que se procuraría resolver las falencias del esquema impuesto en octubre de 1931 y satisfacer, siete meses más tarde, las demandas británicas emergentes del Tratado Roca-Runciman.

A comienzos de 1934, Pinedo explicó la nueva versión del control de cambios, un instrumento para varios objetivos: "Las perspectivas de nuestras exportaciones no hacían entrever la posibilidad de liquidar las deudas de cambio en un futuro inmediato, puesto que el cambio disponible no alcanzaba para las necesidades del corriente año. Se presentaba, pues, ante el gobierno un problema con dos aspectos distintos. El de la cancelación de esa masa de compromisos atrasados, para que no siguiesen presionando sobre el mercado de cambios, y el de evitar que en lo sucesivo continuase la acumulación de nuevos compromisos insatisfechos" (Revista Económica, 1934). $\mathrm{Al}$ analizar al respecto el cuadro $5 \mathrm{y}$ sus interesantes

\footnotetext{
${ }^{23}$ Estos son los valores promedio del tipo de cambio en los tres meses que siguieron a la devaluación. El tipo de cambio libre mostraba en ese período una devaluación del $59 \%$.
}

implicancias, se aprecia que en el nuevo régimen habría un tipo de cambio oficial y uno libre. Para acceder a las divisas baratas (tipo de cambio oficial) se distribuirían permisos previos otorgados por la Comisión de Control de Cambios. Esa distribución no sería neutral ni inocente: los permisos de cambio los recibirían en forma prioritaria quienes importaran mercaderías de países con los que se habían firmado convenios de pago y quienes remitieran utilidades y dividendos a esos países ${ }^{24}$. ¿Con quiénes había firmado la Argentina convenios de pago? Hasta ese momento solo con el Reino Unido. En 1934 se agregarían Bélgica, Suiza, los Países Bajos y Alemania, y varios otros países en los años siguientes. En cambio, aquellos países con los que no se habían firmado convenios de pago (el más importante, los Estados Unidos de América) ingresarían sus mercaderías y remitirían sus utilidades y dividendos de acuerdo con el tipo de cambio oficial solo cuando la demanda prioritaria (aquella proveniente de los países con convenios de pago) estuviese satisfecha. Caso contrario, deberían concurrir al mercado libre, por definición más caro: de hecho, en el primer semestre de 1934, el tipo de cambio libre se ubicó en promedio en más de un $20 \%$ sobre el tipo de cambio oficial.

24 No se incluye el pago de la deuda externa porque el Tratado Roca-Runciman dejaba claro que su pago "por un monto razonable" era, como lo había sido en 1931 , la primera prioridad del régimen de control de cambios cualquiera fuera el acreedor.

Reforma del control de cambios de noviembre de 1933

Tipo de cambio libre

\begin{tabular}{ll}
\hline Oferta de divisas & Demanda de divisas \\
\hline Exportaciones no tradicionales & $\begin{array}{l}\text { Importaciones parciales (aproximadamente 40\%) de países } \\
\text { sin convenios de pago }\end{array}$ \\
Inversiones extranjeras & Remesas parciales a países sin convenios de pago \\
Exportaciones a países vecinos & \\
Cultivos regionales & \\
\hline
\end{tabular}

Tipo de cambio oficial

\begin{tabular}{lll}
\hline Oferta de divisas & Gobierno & Demanda de divisas \\
\hline Exportaciones tradicionales & Diferencial de cambios & $\begin{array}{l}\text { Total de importaciones de países con } \\
\text { convenios de pago } \\
\text { Total de remesas hacia países con convenios } \\
\text { de pago }\end{array}$ \\
& & Importaciones parciales (aproximadamente \\
& $60 \%$ ) de países sin convenios de pago \\
& Remesas parciales a países sin convenios de \\
\end{tabular}

Fuente: Pablo Gerchunoff, "Circulando en el laberinto: la economía argentina entre la depresión y la guerra (1929-1939)", Cuadernos de Trabajo IELAT, N 10, Alcalá de Henares, Universidad de Alcalá, 2010. 
¿Cómo se distribuyeron los pagos entre el mercado oficial y el mercado libre en el momento inicial del nuevo régimen? En el período 1934-1935, alrededor del 60\% de las importaciones provenientes de países sin convenios de pago ingresaron por el tipo de cambio oficial y el $40 \%$ por el tipo de cambio libre ${ }^{25}$. Respecto de esos mismos años, el Reino Unido recibió el 40,2\% del total asignado por el mercado oficial de cambio, cuando el porcentaje había sido del $33,7 \%$ en 1933 , o sea, antes de la reforma del régimen de control de cambios. Con el tiempo, el bilateralismo se extendió. Varios países con un comercio deficitario con la Argentina, incluidos Francia e Italia, firmaron tratados comerciales con sesgo al intercambio compensado.

Hasta aquí se ha pintado el cuadro de las ventajas británicas, obtenidas en las negociaciones del Tratado Roca-Runciman y plasmadas en el diseño del nuevo régimen de control de cambios. Hubo, no obstante, algún margen de maniobra para que las autoridades argentinas pusieran en marcha políticas propias. Por ejemplo, en la lógica de "comprar a quien nos compra", la firma de convenios de pago con varios países en los años siguientes redujo en términos relativos las ventajas británicas, aunque las mantuvo respecto del competidor más importante, los Estados Unidos de América. Además, entre el tipo de cambio comprador y el tipo de cambio vendedor del segmento oficial se fijó un margen de cambio que operó como un impuesto a las exportaciones tradicionales, una porción del cual fue asignada al pago de la deuda pública y otra a sostener el precio de los agricultores a través de la Junta Nacional de Granos, creada para tal efecto. El impuesto a las exportaciones tradicionales limitaba la eventual expansión de la oferta doméstica de productos agropecuarios, y habría de convertirse en un clásico de la política económica argentina en gran parte de los ochenta años subsiguientes. Hay dos posibles explicaciones para esa decisión. Por una parte, la convicción de que en ese contexto internacional era difícil vender más en los mercados internacionales y que el intento produciría una baja del precio de estos productos dado el peso de la Argentina en las exportaciones mundiales (véase el

\footnotetext{
25 Esta es una estimación basada en Salera (1941), pero el porcentaje que se comercializaba en cada mercado sería cambiante en el tiempo de acuerdo con la disponibilidad de divisas. Asimismo, el porcentaje de autorizaciones en el mercado oficial que recibía cada país dependía de varios factores, entre ellos del tipo de bienes que se importaban. Las prioridades eran los bienes intermedios, las materias primas y en menor medida los bienes de capital. Por ejemplo, el mismo Salera señala que en el caso de los Estados Unidos de América, el porcentaje de importaciones que pasó por el mercado oficial fue del 35\%, el $46 \%$ y el $60 \%$ en 1935,1936 y 1937 , respectivamente, lo que da un promedio aproximado del $50 \%$.
}

gráfico 1). Por otra, que era necesaria una protección mayor para impulsar el desarrollo de la industria, un proceso que aparecía con el paso del tiempo como el único camino para sostener el acceso a bienes manufacturados, dado el cambio en los mercados internacionales y su impacto en la capacidad de exportación.

A su vez, las exportaciones no tradicionales, las exportaciones a países vecinos (naturalmente el objetivo apetecible era el Brasil) y una fracción no menor de los productos provenientes de las economías regionales pasarían por el tipo de cambio libre (casillero superior izquierdo del cuadro 5). Esa era una apuesta más de largo plazo a objeto de diversificar productos y destinos de las exportaciones. Si se tenía éxito, se ganaría independencia con respecto a las imposiciones bilateralistas británicas. En esta línea, cuando en 1940 Federico Pinedo retornó al Ministerio de Hacienda estuvo muy cerca de alcanzar un acuerdo de unión aduanera con el Brasil, que se frustró por la desconfianza mutua y el nacionalismo económico que predominaba entre los militares de ambos países ${ }^{26}$.

Las innovaciones en la política económica argentina, como la creación del Banco Central, la moneda fiduciaria y el nuevo régimen de control de cambios con tipos de cambio múltiples (véase el gráfico 5 ) $^{27}$, se extendieron temporalmente en sus trazos gruesos. Sin embargo, su aplicación tuvo rasgos específicos durante los años treinta en comparación con lo que luego sobrevendría. El Banco Central llevó adelante una política monetaria anticíclica que no se repetiría, al menos como regla sistemática. El control de cambios, con las características salientes del régimen de noviembre de 1933, habría de mantenerse durante casi toda la década: tipos de cambio múltiples y ninguna restricción cuantitativa a las importaciones. De ello se desprende que no hubo en esos años un mercado paralelo de cambios ${ }^{28}$. Ante la disminución del tipo de cambio en el mercado libre, en 1935 se crearía un impuesto por el cual las importaciones

\footnotetext{
26 Aquí se hace referencia al Tratado de Libre Cambio Progresivo firmado por la Argentina y el Brasil el 21 de noviembre de 1941. El proyecto, propuesto por Pinedo, concedía las ventajas de la industrialización pesada del lado brasileño, lo que fue vetado por los militares argentinos. Por otra parte, la neutralidad argentina durante la Guerra Mundial frente al alineamiento brasileño con los aliados terminó definitivamente con el Tratado (Porcile, 1995).

${ }^{27}$ Presentar al Banco Central y al régimen de control de cambios como innovaciones solo tiene sentido en la secuencia histórica argentina. Otros países de Europa y de América Latina las habían adoptado antes, cada uno con sus especificidades (Ortiz, 2014).

${ }^{28}$ A diferencia de ello, el régimen de control de cambios de octubre de 1931 había dado lugar a un mercado paralelo, conocido como la "bolsa negra", con una brecha con el tipo de cambio oficial del orden del $40 \%$.
} 
GRÁFICO 5

Los múltiples tipos de cambio a partir de noviembre de 1933

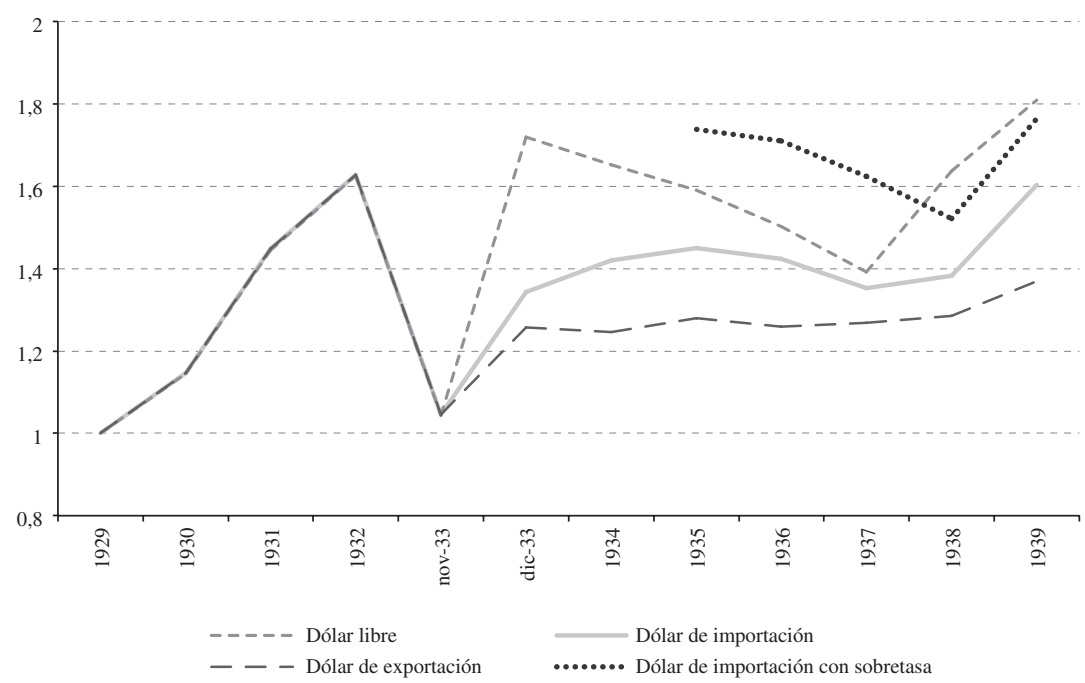

Fuente: Elaboración propia sobre la base de Virgil Salera, Exchange Control and the Argentine Market, Nueva York, University of Columbia Press, 1941; y Revista de Estudios Económicos (varios números).

o transferencias no autorizadas se harían a un tipo de cambio cuya diferencial con el mercado oficial no sería menor del $20 \%$ (veáse el gráfico 5) ${ }^{29}$. Esta modificación estaba en línea con los privilegios acordados al Reino Unido en 1933 y que luego se extendieron a todos los países con convenios de pagos. Recién a fines de 1938 se impondrían restricciones a las importaciones por el mercado libre de cambios y ese fue el comienzo de otro esquema cambiario que caracterizaría a gran parte de las siguientes dos décadas.

Lo cierto es que el patrón oro había quedado atrás. El convencimiento de que esa era una salida definitiva se fundaba en esos dos pilares de la política económica que acabamos de mencionar y describir brevemente: la creación del Banco Central con objetivos poco compatibles con el patrón oro y un régimen de control de cambios con tipos de cambio múltiples. A partir de 1933, la economía argentina comenzó un período de recuperación que, con altibajos, habría de caracterizar a los restantes años de esa década. ¿Sirvieron las novedades de política económica de comienzos de los años treinta para sacar a la economía de la depresión y la deflación? $\mathrm{Al}$ parecer ayudaron, pero no fueron determinantes.

\footnotetext{
${ }^{29}$ La existencia de tipos de cambio múltiples generó un mecanismo que se volvió clásico como fue la subfacturación de exportaciones. En 1936, el gobierno decidió que las exportaciones catalogadas como tradicionales por la Comisión de Cambios del Banco Central quedaran sujetas a aforos (De León, 2014).
}

La devaluación del tipo de cambio fomentó una mayor sustitución de importaciones y el consecuente crecimiento industrial compensó en gran medida el deterioro de los precios agropecuarios y evitó, junto con la creación de dinero fiduciario por financiamiento a los bancos y al Tesoro, una mayor deflación y una crisis financiera. La disminución de la tasa real de interés asociada a la menor deflación y su reversión a fines de 1933 a tasas positivas de inflación, junto con las refinanciaciones bajo condiciones ventajosas ofrecidas por el Banco Nación y el Banco Hipotecario, se inscriben entre los factores que estimularon la recuperación. En cambio, es difícil encontrar elementos expansivos en la política fiscal, al menos hasta 1933, ya que la reducción del déficit fiscal en plena recesión fue de 2,5 puntos del producto. A partir de 1933, y en un contexto donde la restricción externa había dejado de ser la principal limitante al crecimiento, la política fiscal fue levemente procíclica y por ende expansiva, pero ese rasgo fue compensado parcialmente por la política contracíclica del Banco Central en la segunda mitad de la década ${ }^{30}$. No obstante, más allá de las contribuciones de la política económica, según los autores de este trabajo, el factor

${ }^{30}$ El leve aumento del déficit fiscal a partir de 1933, en un contexto de recuperación del nivel de actividad económica, implica que el déficit fiscal estructural estaba aumentando, con su consiguiente repercusión en la demanda agregada. 
más importante para explicar la recuperación fueron los síntomas positivos que comenzaba a mostrar la economía mundial. La expresión de estos cambios globales en la Argentina fue el aumento de los precios internacionales de los productos de exportación y la reversión de las expectativas negativas desde fines de $1932^{31}$. Algo había

${ }^{31}$ En agosto de 1932, Prebisch (1932b) especulaba que las mejoras todavía incipientes en los mercados financieros y en algunos precios de empezado a mutar irreversiblemente, y muy pronto esa transformación se haría visible para todos y abriría el camino a otro cambio ya no macroeconómico, sino de carácter estructural.

Se había salido del laberinto. Si bien otros laberintos esperaban en el futuro a la política económica.

exportación se traducirían a corto plazo en una expansión productiva generalizada.

\section{Bibliografía}

Alhadeff, Peter (1985), "Dependencia, historiografía y objeciones al Pacto Roca", Desarrollo Económico, vol. 25, № 99, Buenos Aires, Instituto de Desarrollo Económico y Social (IDES).

Bacon Lois B. y Friedrich C. Schloemmer (1940), World Trade in Agricultural Products. Its Growth, its Crisis and the New Trade Policies, Roma, Instituto Internacional de Agricultura.

Banco Central de la República Argentina (1938), Memoria Anual, Buenos Aires.

Banco de la Reserva Federal de Saint Louis [en línea] http://research. stlouisfed.org/fred2.

Bolsa de Comercio de Buenos Aires (varios números), Boletín Oficial de la Bolsa de Comercio, Buenos Aires.

Campos, Martín (2005), "El cierre de la caja de conversión en 1929. Una decisión de política económica", Desarrollo Económico, vol. 44, $\mathrm{N}^{\circ} 176$, Buenos Aires, Instituto de Desarrollo Económico y Social (IDES).

CEPAL (Comisión Económica para América Latina y el Caribe) (1977), "Relación de precios de intercambio 1928-1976", Santiago, inédito.

Comité Nacional de Geografía (1942), Anuario geográfico argentino, Buenos Aires.

Congreso de la Nación (1933), Diario de sesiones de la Cámara de Senadores, Buenos Aires.

Copland, Douglas (1934), Australia in the World Crisis, 1929-1933, Cambridge, Cambridge University Press.

Cortes Conde, Roberto (2014), "De la Caja de Conversión al Banco Central", Historia de las Instituciones Monetarias Argentinas, Roberto Cortes Conde, Laura D'Amato y Javier Ortiz Batalla (eds.), Temas Grupo Editorial.

De León, Gonzalo (2014), "Causas y características del control de cambio-Argentina, 1931-1958", Tesis, Universidad Torcuato Di Tella.

De Paiva Abreu, Marcelo (1984), "La Argentina y Brasil en los años treinta. Efectos de la política económica internacional británica y estadounidense", América Latina en los años treinta. El papel de la periferia en la crisis mundial, Rosemary Thorp (comp.), Ciudad de México, Fondo de Cultura Económica.

Della Paolera, Gerardo y Alan Taylor (2003), Tensando el ancla. La caja de conversión argentina y la búsqueda de la estabilidad macroeconómica, 1880-1935, Buenos Aires, Fondo de Cultura Económica.

Eichengreen, Barry (1995), Golden Fetters: the Gold Standard and the Great Depression 1919-1939, Nueva York, Oxford University Press.

Eichengreen, Barry y Jeffrey Sachs (1985), "Exchange rates and economic recovery in the 1930s", The Journal of Economic History, vol. 45, $\mathrm{N}^{\circ}$ 4, Cambridge, Cambridge University Press.

Eichengreen, B. y M. Flandreau (2009), "The rise and fall of the dollar (or when did the dollar replace sterling as the leading reserve currency?)", European Review of Economic History, vol. 13, $\mathrm{N}^{\circ} 3$, Oxford University Press.
Findlay, Ronald y Kevin O'Rourke (2007), Power and Plenty: Trade, War and the World Economy in the Second Millennium, Princeton, Princeton University Press.

Fodor, Jorge y Arturo O’Connell (1973), "La Argentina y la economía atlántica en la primera mitad del siglo xx", Desarrollo Económico, vol. 13, $\mathrm{N}^{\circ} 49$, Buenos Aires, Instituto de Desarrollo Económico y Social (IDES).

Gerchunoff, Pablo (2010), "Circulando en el laberinto: la economía argentina entre la depresión y la guerra (1929-1939)", Cuadernos de Trabajo IELAT, $\mathrm{N}^{\circ}$ 10, Alcalá de Henares, Universidad de Alcalá.

Gerchunoff, Pablo y José Luis Machinea (2015), "Reestimación de los términos de intercambio de la Argentina durante la década de 1930", inédito.

Hanson, John (1980), Trade in Transition: Exports from the Third World, 1840-1900, Nueva York, Academic Press.

Magariños, Mateo (1991), Diálogos con Raúl Prebisch, Ciudad de México, Fondo de Cultura Económica.

O’Connell, Arturo (1984), "La Argentina en la depresión: los problemas de una economía abierta", América Latina en los años treinta. El papel de la periferia en la crisis mundial, Rosemary Thorp (comp.), Ciudad de México, Fondo de Cultura Económica.

Ortiz, Javier (2014), "Los bancos centrales en América Latina", Editorial Sudamericana.

Prebisch, Raúl (1932a), "La acción de emergencia en el problema monetario", Revista Económica, vol. 5, № 2, Buenos Aires. (1932b), "El momento presente de la crisis internacional", Revista Económica, vol. 5, ํㅜ 7, Buenos Aires.

Porcile, Gabriel (1995), "The challenge of cooperation: Argentina and Brazil, 1939-1955", Journal of Latin American Studies, vol. 27, $\mathrm{N}^{\circ} 1$, Cambridge, Cambridge University Press.

República Argentina (1938), Poder Ejecutivo Nacional 1932-1938, vols. 1 y 2, Buenos Aires.

Revista de Economía Argentina (1929-1934), Buenos Aires.

Revista de Estudios Económicos (varios números), Buenos Aires.

Revista Económica (1934), Buenos Aires.

Salama, Elías (2000), "La Argentina y el abandono del patrón oro", Documento de Trabajo, $\mathrm{N}^{\circ} 28$, Facultad de Ciencias Económicas, Universidad Nacional de La Plata.

Salera, Virgil (1941), Exchange Control and the Argentine Market, Nueva York, University of Columbia Press.

Shearer, Ronald y Carolyn Clark (1984), "Canada and the interwar gold standard, 1920-35: monetary policy without a central bank", A Retrospective on the Classical Gold Standard, 18211931, Michael Bordo y Anna Schwartz (ed.), Chicago, The University of Chicago Press.

Sociedad de las Naciones (1933), Statistical Yearbook 1932-1933, Ginebra.

Vásquez-Presedo, Vicente (1976), Estadísticas históricas argentinas II (comparadas), Buenos Aires, Ediciones Macchi.

Wells, H.G. (1933), “The Shape of Things to Come”, inédito. 